\title{
ДИАГНОСТИКА РАЗВИТИЯ ИНДИВИДУАЛЬНОСТИ ДЕТЕЙ В ПРОЦЕССЕ ОСВОЕНИЯ КУЛЬТУРНОЙ ПРАКТИКИ СОЦИАЛЬНО-НРАВСТВЕННОГО ПОВЕДЕНИЯ В ОБЩЕНИИ СО СВЕРСТНИКАМИ
}

\section{DIAGNOSTICS OF THE DEVELOPMENT OF INDIVIDUALITY OF CHILDREN IN THE PROCESS OF MASTERING THE CULTURAL PRACTICE OF SOCIAL AND MORAL BEHAVIOR IN COMMUNICATION WITH PEERS}

\section{Lavrinets}

Summary: The article presents the substantiation of the specifics of the pedagogical diagnostics of the individuality of a preschool child in the development of the practice of social and moral behavior; substantiated effective methods of diagnosing a child's real moral choice in communicating with peers and generalizing the results of diagnostics in the form of an individual profile of the practice of social and moral behavior.

Keywords: cultural practices, moral behavior, moral norms, pedagogical diagnosis, individual profile of the practice of social and moral behavior, individual educational route.
$\mathrm{O}$ дним из важнейших методологических оснований современного дошкольного образования является культурологический подход, согласно которому развитие ребенка следует рассматривать не только как введение ребенка в мир человеческой культуры, но и как становление ребенка в качестве субъекта культуры, когда создается индивидуальный культурный опыт конкретного ребенка (Н.Б. Крылова, В.Т. Кудрявцев и др.).

Особую роль в процессе развития ребенка в качестве субъекта культуры выполняют культурные практики ребенка. Характеризуя сущность культурных практик, Н.Б. Крылова указывает на то, что они представляют собой самостоятельные практики разнообразной по содержанию деятельности и инициативного поведения детей.

Как подчеркивает Н.Б. Крылова: «Ребенок развивается...благодаря получению нового опыта собственными силами организованной деятельности...Ценны его инициативные пробы своей новой способности, самостоятельное предугадывание собственного личностного
Лавринец Ирина Александровна

К.п.н., дочент, Волгоградский государственный сочиально-педагогический университет, г. Волгоград Lavrinets1@yandex.ru

Аннотация: В статье представлено обоснование специфики педагогической диагностики индивидуальности ребенка дошкольного возраста в освоении практики социально-нравственного поведения; обоснованы эффективные способы диагностики реального нравственного выбора ребенка в общении со сверстниками и обобщения результатов диагностики в виде индивидуального профиля практики социально-нравственного поведения.

Ключевые слова: культурные практики, нравственное поведение, моральные нормы, педагогическая диагностика, индивидуальный профиль практики социально-нравственного поведения, индивидуальный образовательный маршрут.

роста» $[3, c .84]$.

Содержанием индивидуального культурного опыта ребенка выступает многообразная апробация им своих возможностей в совместной деятельности со взрослыми и сверстниками, в самостоятельной деятельности.

Культурные практики, по мнению Н.Б. Крыловой, позволяют детям осваивать разнообразное содержание культуры: практика обустройства собственного культурного пространства; практика общение со значимым взрослым в семье; практика познания и самостоятельное учение; нравственные нормы практики общения и взаимодействия; практика участия в хозяйственной и деловой жизни семьи; культурное пространство чтения и первый опыт литературного творчества; художественная практика и овладение основами музыкальной культуры; коллекционирование; практика посещения культурных учреждений и культурно-массовых мероприятий; практика работы с компьютером [3].

Результатом освоения детьми культурных практик, 
с одной стороны, является освоение детьми универсальных культурных умений, которые обеспечивают его активную социальную и продуктивную деятельность вхождение в мир культуры, а с другой стороны, становление индивидуальности ребенка. Именно специфические особенности культурных практик как самостоятельных проб ребенка создают возможности для становления и развития индивидуальности каждого ребенка.

Культурные практики нравственного поведения в общении со сверстниками активно осваиваются детьми с 5 лет. Это обусловлено тем, что именно с 5 лет возрастает потребность ребенка в общении и взаимодействии со сверстниками. Успешность взаимодействия со сверстниками требует от каждого ребенка самоопределения по применению нравственных норм и правил, помогающих согласовать запросы и желания детей таким образом, чтобы ситуация совместных действий воспринималась как эмоционально комфортная и полезная для большинства участников.

Как подчеркивает Авдулова Т.П., общение со сверстниками становится мощной движущей силой процесса интериоризации молральных норм и способствует формированию внутренних регуляторов нравственного поведения [1].

Культуру нравственного поведения определяют нравственные ценности и нормы, согласно которым признается приоритет интересов большинства в обществе и необходимость сознательного ограничения каждым отдельным субъектом своих запросов и намерений для достижения «блага» другого человека (людей). Осознание нравственных норм и ценностей, их активное применение во взаимодействии с другими людьми, способствует восприятию другого человека как значимого, развитию у детей готовности и способности принимать этого человека таким, каков он есть, требует умения договариваться о продуктивных совместных действиях в значимой для обеих сторон ситуациях.

Принимая во внимание, что сознание и самосознание детей дошкольного возраста отличается центрацией на собственном мироощущении, освоение детьми практики социально-нравственного поведения является длительным и социально обусловленным процессом осознавания детьми нравственных ценностей и норм, обеспечивающих успех в достижении согласованности в совместной деятельности при условии расширения эмоционального опыта, проживание детьми гуманных чувств (сопереживания, симпатии, сорадования, отзывчивости, чувства справедливости).

Характеризуя нравственные нормы практики общения и взаимодействия, Н.Б. Крылова подчеркивает, что «ребенку надо привыкнуть к ситуации выбора и решению нравственной дилеммы собственными средствами» [3, с.88].

Опыт нравственного поведения у каждого ребенка по своему индивидуален и обусловлен нравственными ценностями каждой семьи, нравственными установками родителей по воспитанию детей, способностью родителей транслировать детям свой опыт ценностного принятия членов семьи, а также опыт разрешения конфликтных ситуаций, которые естественным образом возникают в жизни каждой семьи. Соответственно, во взаимодействии со сверстниками в группе детского сада каждый ребенок попадает в проблемные ситуации, когда его индивидуальный нравственный опыт не совпадает, а иногда даже противоречит опыту других детей, а также может противоречить тем нравственным нормам, которые формируются у детей в педагогическом процессе дошкольного учреждения.

Основу нравственного поведения детей в группе детского сада составляют развивающиеся и усложняющиеся межличностные отношения между детьми. Опыт таких отношений во многом влияет на отношение ребенка к себе и другим, к социальному миру в целом не только в период дошкольного детства, но и в дальнейшем во взрослой жизни.

Как отмечает Смирнова Е.О., у детей дошкольного возраста имеют место существенные индивидуальные варианты отношения к сверстникам, обусловленные различиями в выраженности предметного и личностного отношения к сверстнику. Когда в поведении детей преобладает предметное отношение, они стремятся отстаивать свои преимущества, а другой ребенок воспринимается как конкурент, используется для достижения своих намерений, что порождает между детьми конфликты и негативные эмоции обиды, зависти, злости. Личностное отношение к сверстникам характеризуется безоценочной эмоциональной вовлеченностью в деятельность и переживания сверстника, стремлением следовать в своем поведении базовым нравственным ценностям - добра и справедливости [6].

В нравственном развитии детей дошкольного возраста процесс формирования представлений о нравственных нормах и правилах опережает развитие нравственного поведения. Сложность самостоятельного проявления социально-нравственного поведения детей состоит в том, что оно предполагает добровольное применение нравственных норм при отсутствии внешнего контроля со стороны взрослых [1].

Смирнова Е.О. подчеркивает: «В опыте непосредственного взаимодействия с другими людьми, особен- 
но со сверстниками, ребенок объединяет свое знание о должном с теми чувствами, которые он испытывает по отношению к партнеру по общению» $[6, c .46]$.

Необходимость определения индивидуального пути освоения детьми практики социально-нравственного поведения требует осуществления мониторинга для организации педагогической поддержки нравственного развития каждого ребенка. В связи с этим актуальной исследовательской задачей становится выбор критериев и способов диагностики индивидуальных проявлений детей в практиках социально-нравственного поведения и общения со сверстниками.

Итак, цель нашего исследования состояла в том, чтобы выявить индивидуальные профили практики социально-нравственного поведения детей старшего дошкольного возраста в общении и взаимодействии со сверстниками.

Мы полагаем, что психологическим механизмом развития социально-нравственного поведения детей является принятие ими решения в ситуациях нравственного выбора с учетом базовых нравственных норм. Исходя из этого, в качестве критерия для оценки индивидуального профиля нравственного поведения детей нами был выбран критерий морального мышления - способность действовать по сознательно принятому намерению в ситуациях нравственного выбора.

Для проведения диагностики морального мышления детей была использована авторская методика Авдуловой Т.П. «Моральные дилеммы (ситуации для дошкольного возраста». Моральные дилеммы позволяют выявить суждения детей по таким моральным нормам, которые активно применяются детьми в условиях совместной деятельности и общения со сверстниками: нормы помощи, справедливости и честности [1].

При этом в предлагаемых незаконченных историях взаимодействия со сверстниками ребенку необходимо было сделать два выбора. Первый - реальный выбор, когда ребенок идентифицирует себя с персонажами истории, применяя свой индивидуальный опыт нравственного поведения. И второй - формальный выбор, ориентированный на знание ребенком «должного» в той же ситуации, что отражает способность ребенка обосновать универсальность нравственной нормы.

Процедура оценки каждого решения детей по трем ситуациям, в соответствии с методикой, включала в себя ранжирование от 0 до 6 баллов, соответственно - от ответов детей, которые никак не были связаны с моральными нормами, до использования детьми в своих решениях обобщенной нравственной нормы. По каждому выбору (реальному и формальному) определялся средний балл по всем проблемным ситуациям (дилеммам). Такой подход позволяет определить индивидуальный профиль реального нравственного поведения каждого ребенка, т.е. активное применение им той или иной нравственной нормы в общении и взаимодействии со сверстниками.

Диагностика индивидуального профиля практики социально-нравственного поведения детей была проведена на базе дошкольного образовательного учреждения г. Волгограда, в которой приняли участие дети старшего дошкольного возраста (22 ребенка).

Нам представляется важным для осуществления педагогами дошкольного учреждения мониторинга освоения детьми практики социально-нравственного поведения детей применение диаграммы для визуализации динамики изменений индивидуального профиля практики реального социально-нравственного поведения. В такой диаграмме наглядно обозначены уровни инициативного применения детьми нравственных норм в общении со сверстниками и ресурсы развития опыта нравственного поведения каждого ребенка.

Результаты определения индивидуального профиля практики социально-нравственного поведения детей представлены в диаграмме, в которой показано соотношение реального и формального выборов в ходе реше-

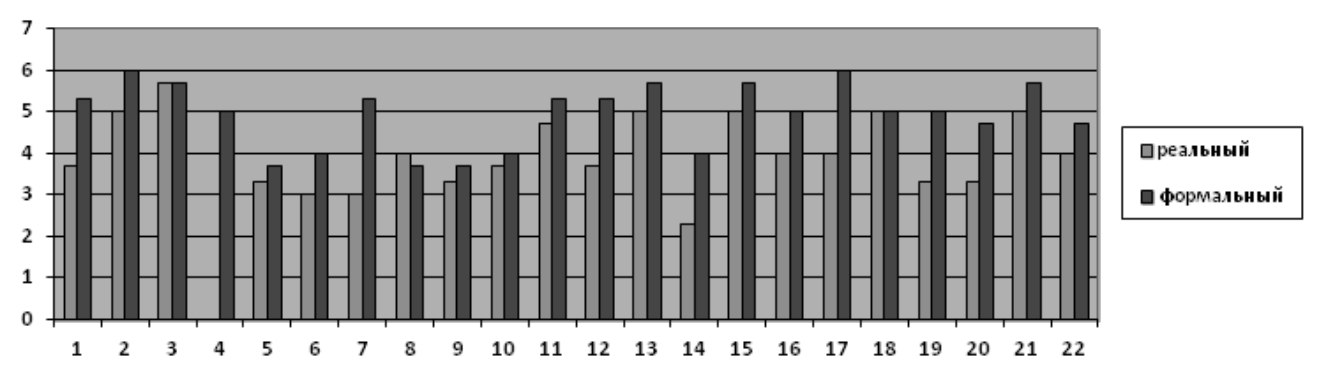

Рис. 1. Диаграмма результатов диагностики индивидуального профиля практики социально-нравственного поведения детей старшего дошкольного возраста (в ситуациях морального выбора) 
Таблица 1.

Примеры результатов детей с высоким средним баллом реального выбора нравственного поведения

\begin{tabular}{l|c|c|c|c|c|c|}
\multirow{2}{*}{$\begin{array}{l}\text { № } \\
\text { Респондента } \\
\text { (дети) }\end{array}$} & \multicolumn{2}{|c|}{ Помощи Нравственные нормы } & \multicolumn{3}{c|}{ Щедрости } \\
\cline { 2 - 7 } & $\begin{array}{c}\text { Реальный выбор } \\
\text { (в бал.) }\end{array}$ & $\begin{array}{c}\text { Формальный } \\
\text { выбор } \\
\text { (в бал.) }\end{array}$ & $\begin{array}{c}\text { Реальный выбор } \\
\text { (в бал.) }\end{array}$ & $\begin{array}{c}\text { Формальный } \\
\text { выбор } \\
\text { (в бал.) }\end{array}$ & $\begin{array}{c}\text { Реальный выбор } \\
\text { (в бал.) }\end{array}$ & $\begin{array}{c}\text { Формальный } \\
\text { выбор } \\
\text { (в бал.) }\end{array}$ \\
\hline 2 & 5 & 6 & 4 & 6 & 6 & 6 \\
\hline 3 & 5 & 5 & 3 & 6 & 3 & 5 \\
\hline 19 & 5 & 5 & 6 & 4 & 4 & 6 \\
\hline
\end{tabular}

Таблица 2.

Примеры результатов детей с низким средним баллом реального выбора нравственного поведения

\begin{tabular}{|c|c|c|c|c|c|c|}
\hline \multirow{3}{*}{$\begin{array}{l}\text { № } \\
\text { Респондента } \\
\text { (дети) }\end{array}$} & \multicolumn{6}{|c|}{ Нравственные нормы } \\
\hline & \multicolumn{2}{|c|}{ Помощи } & \multicolumn{2}{|c|}{ Честности } & \multicolumn{2}{|c|}{ Щедрости } \\
\hline & $\begin{array}{l}\text { Реальный выбор } \\
\text { (в бал.) }\end{array}$ & $\begin{array}{c}\text { Формальный } \\
\text { выбор } \\
\text { (в бал.) }\end{array}$ & $\begin{array}{c}\text { Реальный выбор } \\
\text { (в бал.) }\end{array}$ & $\begin{array}{c}\text { Формальный } \\
\text { выбор } \\
\text { (в бал.) }\end{array}$ & $\begin{array}{c}\text { Реальный выбор } \\
\text { (в бал.) }\end{array}$ & $\begin{array}{c}\text { Формальный } \\
\text { выбор } \\
\text { (в бал.) }\end{array}$ \\
\hline 6 & 3 & 6 & 2 & 2 & 4 & 4 \\
\hline 7 & 5 & 6 & 0 & 6 & 4 & 4 \\
\hline 14 & 5 & 5 & 1 & 1 & 1 & 6 \\
\hline
\end{tabular}

ния моральных дилемм каждым ребенком.

Анализ результатов диагностики свидетельствует о том, что для детей с высоким уровнем практики реального социально-нравственного поведения (средний балл равен 5 и 5,7 у детей - № 2, 3, 13, 15, 18,21) характерно принятие решения в ситуациях морального выбора с ориентацией на моральную норму помощи и это обусловлено стремлением детей к сопереживаю и уважению чувств другого человека.

В содержании индивидуального профиля практики социально-нравственного поведения важно зафиксировать с помощью выбранной методики, какие нравственные нормы наиболее активно влияют на принятие каждым ребенком решения в ситуациях нравственного выбора.

Приведем примеры результатов диагностики реальных выборов детьми нравственных норм с высокими и низкими показателями по трем нормам - помощи, честности и щедрости.

Представленные результаты свидетельствуют об общей закономерность нравственного развития детей дошкольного возраста, что формирование представлений детей о нравственных нормах опережает развитие их реального нравственного поведения, а знание мораль- ных норм не всегда обеспечивает их применение детьми в реальной жизненной ситуации.

Но четкое знание педагогами дошкольных учреждений индивидуального профиля нравственного развития каждого ребенка создает возможности для проектирования индивидуального образовательного маршрута.

Индивидуальный образовательный маршрут мы рассматриваем как целенаправленно проектируемый и организованный педагогами персональный путь развития и реализации личностного потенциала и индивидуальности ребенка. Для проектирования практики социально-нравственного поведения конкретного ребенка оптимален интегрированный тип индивидуального образовательный маршрута, сочетающего в себе компоненты расширения и углубления содержания образовательной деятельности с ребенком.

Целенаправленно обогащая нравственное содержание детской деятельности, совершенствуя способы принятия решений детей в различных ситуациях взаимодействия со сверстниками, обеспечивая принятие детьми нравственной мотивации индивидуальной и совместной деятельности, педагоги способствует накоплению дошкольниками ценной практики нравственного поведения. 


\section{ЛИТЕРАТУРА}

1. Авдулова Т.П. Диагностика и развитие моральной компетентности личности дошкольника: Психолого-педагогическая служба сопровождения ребенка. Методическое пособие / Т.П. Авдулова, Е.Г. Аксенова, Т.Н. Захарова / Под общ.ред. Т.П. Авдуловой. - М.: Гуманитарный изд. центр ВЛАДОС, 2014. - 127 с.

2. Езопова С.А., Солнцева 0.В. Проектирование педагогической диагностики индивидуального развития детей. - Детский сад: теория и практика. - 2015. №2. - c. 54-67.

3. Крылова Н.Б. Культурные практики детства и их роль в становлении культурной идеи ребенка // Самобытность детства. Новые ценности образования. 2007. Вып. 3 (33). С. 79-102.

4. Лебедева С.А. Индивидуализация развития дошкольников. - Детский сад: теория и практика.- 2015. - № 2.

5. Овчарова Р.В., Мельникова Н.В. Нравственное развитие ребенка на основе освоения базисных этических понятий. - Вестник КГУ. - 2010. - № 2. - с.26-30.

6. Смирнова Е.О., Холмогорова В.М. Межличностные отношения дошкольников: Диагностика, проблемы, коррекция. - М.: Гуманит. изд. центр ВЛАДОС, 2014. $-160 \mathrm{c}$.

( ) Лавринец Ирина Александровна (Lavrinets1@yandex.ru).

Журнал «Современная наука: актуальные проблемы теории и практики»

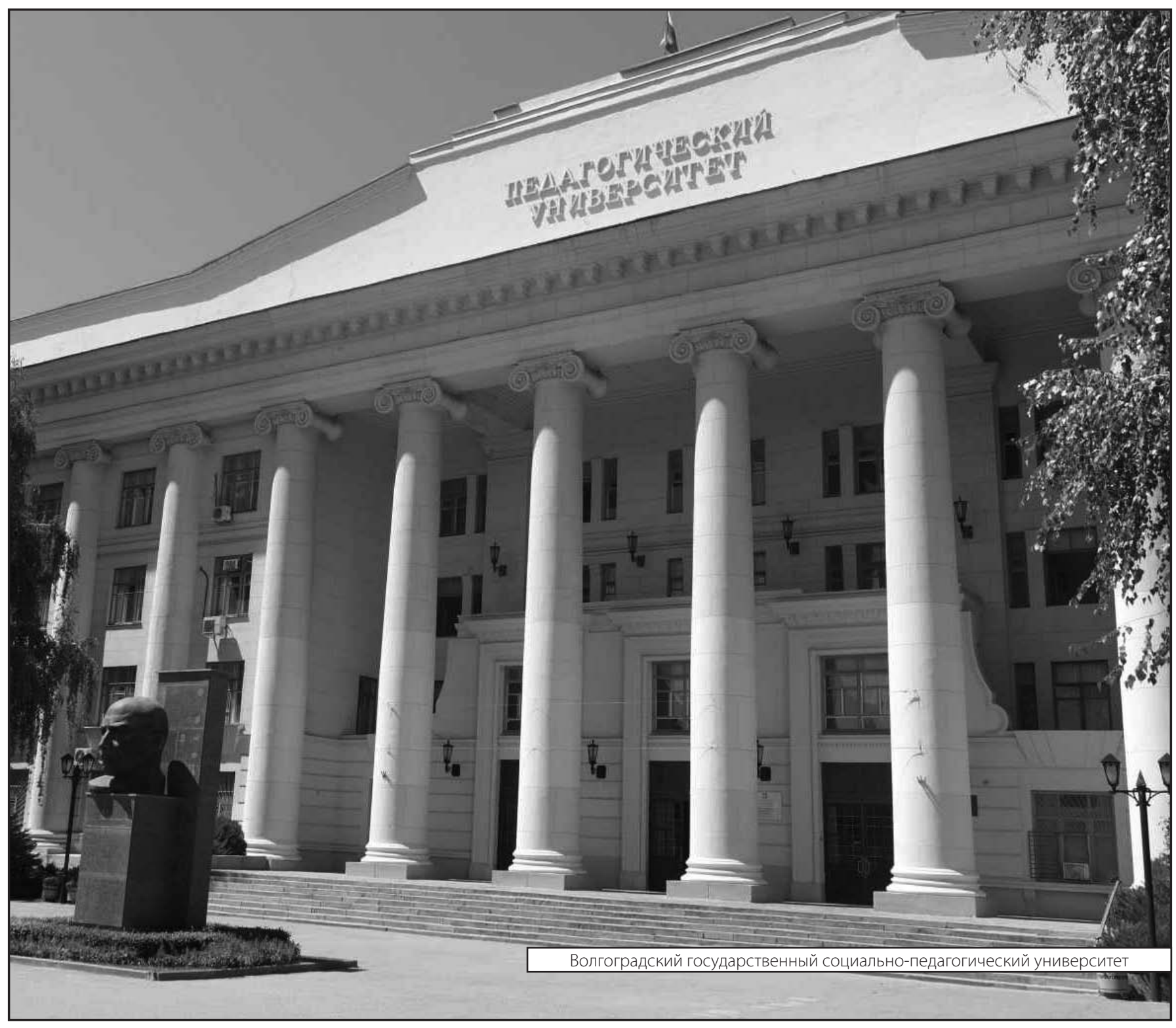

